\title{
Market Analysis of Soundproof and Noise Reduction Plate
}

\author{
Heyu Chang ${ }^{1, *}$ and Yaxing Wang ${ }^{2}$ \\ ${ }^{1}$ Management Science and Engineering Department, Zhengzhou University, Henan Province, China \\ ${ }^{2}$ Management Science and Engineering Department, Zhengzhou College, Henan Province, China \\ Corresponding Email: 1406987621@qq.com
}

\begin{abstract}
Since the reform and opening up, China has a booming economy development, transportation industry as an important part of the economic processes has made a considerable progress, and continue to promote the rapid economic development. At the end of 2012, China's highway mileage has reached 4.238 million $\mathrm{km}$ and highway mileage ranks first in the world. Transportation in promoting rapid economic development, but also brings the traffic noise which has a tremendous influence on residents' daily life, and this influence has gradually deepening and widening, in this situation the production of noise reduction panel gradually emerged. In this paper, a noise barriers manufacturer' business model in Beijing Daxing District and analyze existing data will be analyzed, it will give much guidance and reference for a new noise reduction factory. The study has shown that plant will target all levels of government departments in charge of roads and the property of management department of residence as our customer groups, increasing technological innovation and improving product quality to establish a more extensive business relationships, and gradually formed noise barriers market competitiveness.
\end{abstract}

\section{Introduction}

The establishment of socialist market economy gradually relaxed the access threshold for enterprises, so small and medium enterprises have sprung up. By the end of 2014, the number of registered small and medium enterprises have reached 42000 thousand, which hold 99 percent amount all registered enterprises in China, and its contribution rate of GDP, tax and employment reached $58.5 \%, 52.2 \%$ and $80 \%$ respectively [1]. There is no doubt that an economic boom and high-speed growth depend on the manufacturing industry because the real economy is the drive for social development. The state-owned economic system reform of last century in 90 s has gradually turned social economic development from the quota system dominated by the major state-owned enterprises to the market competition system dominated by the small and medium enterprises [2]. And the state has encouraged development of small and medium enterprises in terms of preferential tax and opened up a Easy Access for entrepreneurs [3].

A good creative project is the basic premise of success, but not business results. Only through effective action the brain ideas can be transformed into practical productive forces [4]. In this paper, based on the Potter five forces industry analysis, the opportunity and challenge of noise reduction board factory machine will be discussed, and the feasibility of a series of problems of production, price, marketing and finance will be analyzed. Through analyzing the development expectations and possible problems of the noise reduction plate in Beijing Senseshixing Environmental Engineering Department, some countermeasure will be offered for future entrepreneurs.

\section{Marketing analysis of soundproof and noise reduction plate}

\subsection{The definition of soundproof and noise reduction plate}

Soundproof and noise reduction plate is also called noise barrier. Its operating principle is reducing the propagation strength of noise through altering the propagation path of sound artificially, with the aim of soundproof and noise reduction. Noise pollution has become the fourth pollution following solid waste pollution, water pollution, air pollution, and it has huge impact on people's daily lives $[5,6]$. 
According to the survey data from the related organizations of environment ministry in 2014 people's degree of satisfaction of life noise is only $50 \%$, just above their degree of satisfaction of air pollution, ranking second from bottom $[7]$.

With the rapid construction of national highways, railways and people's higher and higher requirement for the quality of living environment, the rapid development phase of the noise barrier industry has begun [8]. The soundproof principle of noise barrier is that acoustic waves are very easy to be a reflected back to sound source when the wavelength of acoustic waves of the noise is smaller than the surface size of the barrier, and thus a sound shadow region where it cannot be affected by the noise is formed behind the noise barrier. It is shown in Figure 1.

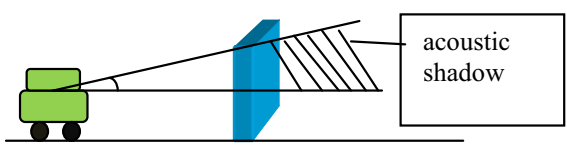

Fig. 1. Acoustic shadow of noise barrier.

\subsection{The market development of noise barrier in China}

Since the policy of China's reform and opening-up was carried out, transportation industry has gotten rapid development. At present highways has covered more than $90 \%$ of the medium-sized city in our country, and total highway mileage ranks first in the world [9]. With the unceasing construction of highways, railways and other transportation facilities, the need for building noise barrier along the road will also be increased accordingly.

So far, the Chinese manufacturers of sound barriers are around 5000 by conservative estimates, and products range from the transparent soundproof PC plate, bridge and railway noise barriers to airport fence noise barriers. There are many manufacturing enterprises in this industry [10]. Based on the different production process and soundproof effects, noise barriers of most manufacturers are priced at 50-400 RMB per square meter. It is shown in Table 1.

Table 1. The price of all kinds of noise barrier(Unit: RMB).

\begin{tabular}{c|c|c|c|c}
\hline $\begin{array}{c}\text { Core } \\
\text { Material } \\
\mathrm{s}\end{array}$ & $\begin{array}{c}\text { Texture } \\
\mathrm{s}\end{array}$ & $\begin{array}{c}\text { Acryli } \\
\mathrm{c}\end{array}$ & $\begin{array}{c}\text { Iron or } \\
\text { zinc } \\
\text { plating }\end{array}$ & $\begin{array}{c}\text { PC soild } \\
\text { sheet }\end{array}$ \\
\hline \multicolumn{2}{c|}{ PC board } & 50 & 100 & 150 \\
\hline Glass wool & 100 & 150 & 200 \\
\hline \multicolumn{2}{c|}{ Rock wool } & 150 & 200 & 300 \\
\hline
\end{tabular}

The price of noise barrier is mainly determined by its internal core material and its external material. The price of noise barrier is the cheapest one if its core material is PC plate and its external material is acrylic, and the market price has maintained at the level of $50 \mathrm{RMB}$ per square meter. The price of noise barrier is about $150 \mathrm{RMB}$ per square meter if its core material is glass wool and its plate is iron plate or galvanized iron plate. The price of noise barrier is the most expensive one if its core material is rock wool and external material is PC plate, and its market price is roughly 300 RMB per square meter.

\subsection{Consumption analysis of noise barrier}

The construction of national railways has leaped forward since 1995. By the end of 2013 China's highway traffic mileage has reached 104468 kilometers, ranking first in the world [11]. The increase of highway mileage adds the possibility to build highways beside cities and towns. it is bound to have certain impact on the residents' daily life along the highway [12]. And it has become the inevitable choice to build noise barrier along the highway to minimize the impact of noise on the residents. Figure 2 reflects market demand growth on China's noise barrier market from 2005 and 2012.

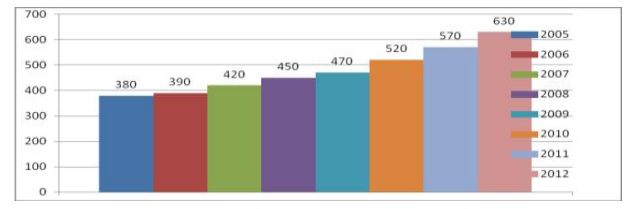

Fig. 2. The market demand of noise barrier from 2005 to 2010. 
Demand for noise barrier is in steady trend of rising, from 3.8 million tons in 2005 (a ton equivalent to 100 square meters) to 6.3 million tons in 2012, and the market demand growth rate reached $65.7 \%$. Looking from the data, the market demand for noise barrier is very big, and the growth of noise barrier has stable momentum. It indicates that investment risk in this field is not particularly big, and it is a relatively stable equipment manufacturing industry that is conducive to the development of the national environmental protection.

\section{External environment analysis of noise barrier market}

\subsection{Customer analysis}

The main group of consumption of noise barrier is government management departments of highway, railway and airport construction at all levels, whose requirement for the quality of noise barrier is relatively high. They are not particularly sensitive to the product price, so more business profits can be gotten. Secondary customers are all kinds of living community built along important arteries. Noise barrier construction bid determines the success or failure of the project, but market share of this part is very big [13]. Scale effect can be obtained by using the strategy of gaining high turnover through meager profit. The rest consumers some service sectors determined by the operating characteristics, such as KTV. Consumer groups of this part pursue the maximization of the soundproof effect, so their bargaining power is low. However, because of the unbalanced development of those places providing leisure service, their market demand is small.

\subsection{Supplier analysis}

The manufacturing technology of noise barrier produced by the environmental protection department of Center INT in Beijing is high, and it involves a good deal of product material. Figure 3 is a simple picture of the noise barrier produced by this company.

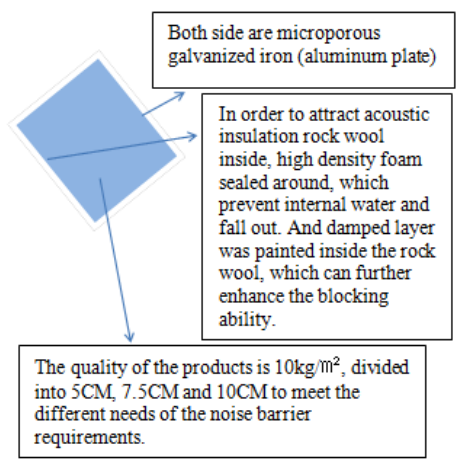

Fig. 3. Simple engineering drawings of noise barrier.

The quality of the noise barrier produced by Center is high. And many suppliers are involved. But the basic raw materials are ordinary industrial products, and there are many suppliers.

\subsection{Competitor analysis}

Competition among noise barriers belongs to differentiation competition of products of the same industry [14]. Along the railways and airports only noise barrier can be used to obtain efficient soundproof and noise reduction effect. According to the product type the competitors' products can be divided into three types. Specific conditions are shown in Table 2.

Table 2. Three main noise barrier product in sound insulation market (Unit:RMB/m²).

\begin{tabular}{l|l|l|l}
\hline $\begin{array}{l}\text { Type of sound } \\
\text { insulation } \\
\text { products }\end{array}$ & Product structure features & Price & Advantages and disadvantages \\
\hline
\end{tabular}




\begin{tabular}{c|l|l|l}
\hline Product one & $\begin{array}{l}\text { The mainly external material } \\
\text { is acrylic and the core } \\
\text { material is PC board. }\end{array}$ & $30-100$ & $\begin{array}{l}\text { Advantages: low cost, low engineering cost, } \\
\text { Suitable for village sound insulation } \\
\text { construction along the way. } \\
\text { Disadvantage: poor noise insulation effect. }\end{array}$ \\
\hline Product two & $\begin{array}{l}\text { The mainly external material } \\
\text { is galvanized sheet and the } \\
\text { core material is fiber cotton } \\
\text { board. }\end{array}$ & $\begin{array}{l}\text { The mainly external material } \\
\text { is senior endurance plate and } \\
\text { the core material is rock } \\
\text { wool. }\end{array}$ & $\begin{array}{l}\text { Advantages: sound insulation effect is good } \\
\text { and its price is moderate. } \\
\text { Disadvantages: waste fiber cotton board can } \\
\text { easily cause pollution. }\end{array}$ \\
\hline Product three & $\begin{array}{l}\text { Around } 300 \\
\text { Advantages: sound insulation effect is the best, } \\
\text { and the product is beautifu. } \\
\text { Disadvantage: higher prices }\end{array}$ \\
\hline
\end{tabular}

The new-established factory is going to produce product type 2 based on the manufacturing technology of Center. The quality of this product is at above the average level in the industry, and it has the characteristics of airproofing, waterproofing, fireproofing, strong surface corrosion resistance, good soundproof effect and moderate price. Thus it can be used to participate in the bidding of government construction projects and serve the program of community noise control. And it can maximize the management efficiency of the company.

\subsection{Substitute analysis}

Noise barrier is the most effective way to solve the problem of traffic noise along the highway, railway and airport. It is difficult to find a substitute. Substitutes with the similar soundproof effect are landscape greening woods along the road such as lawns and trees and concrete block walls. Noise barrier is by far the most effective way to control traffic noise. It not only has good soundproof effect and also less construction difficulty. And the later maintenance is easy. It has the appeal of the landscape. Threat from the substitutes is small.

\subsection{Potential entrants}

With the continuous development of national road construction, development of noise barrier becomes faster and faster. Where there is demand there will be a market. Keen and rational economic men will grasp the opportunity, and become the potential entrants of noise barrier industry. Currently potential entrants include landscaping company and individuals or companies who have operating experience of the noise barrier industry and certain funds.

Opportunities of the industry at present are concluded through the analysis of competition of noise barrier in noise barrier industry: (1) The construction of national infrastructure is striding forward, and noise barrier market will usher in a golden period of development. (2) Noise barrier industry is a capital-intensive as well as technology-intensive industry. The use value of the products can be increased through improving the manufacturing technology and making the production process finer. Space of improvement and reform of noise barrier is large. And it also gives new business opportunities of development. (3) The bargaining power of suppliers and customers is not high, therefore it also ensures timely realization of corporate profits. (4) Substitutes to replace the effect of noise barrier is not obvious. They are unable to completely replace the soundproof and noise reduction effect of noise barrier. Noise barrier can keep the product uniqueness for quite a period of time. (5) The threat of potential entrants is small. Due to the restriction factors of obtaining soundproof effect and practical operation difficulty. It is difficult for the landscaping companies and the all alike to enter the field of noise barrier. Threat mainly comes from competition within the industry. There are more than 5000 enterprises producing soundproof facilities on domestic market. Although the quality of them is uneven, they all can impose a certain impact and influence on fixed market.

\section{Marketing and sales}

\subsection{Market orientation}

\subsubsection{The siting of factories}

Noise barrier factories are manufacturing factories. Their geographical location should be sited in small and medium-sized industrial parks far away from business districts and residential areas. There transportation is convenient, and all kinds of industries cluster in the parks, and complete infrastructure is established. Besides they are far away from the residential and business district, they will not impose much impact on the residents nearby. 


\subsubsection{Customer orientation}

The consumption subject of noise barrier is government administrative departments at all levels of highways, railways and airports. It also includes the medium-to-high grade residential areas near traffic roads and a small number of service sectors needing acoustic environment. For the relevant government departments, companies should use the high quality of soundproof equipment and a price with competitive advantage to win the market.

For buildings near the highways, railways and airports, opinions of related management department about project of building noise barrier should be actively understood. Right of construction of the project should be strived to obtain. For service sectors needing soundproof equipment, customers' bargaining power is low. Although the market is not very big, considerable benefits can still be gotten by selling products at a premium. Therefore this part of market should also be won.

\subsection{Marketing strategy}

\subsubsection{Product strategy}

Most noise barrier has fixed production specifications. Researchers suggest that the object's geometric shape can effectively weaken the noise effect, so noise barrier produced by companies will adopt laced resonant devices to improve soundproof effect. This not only enhances the functionality of noise barrier, and also makes the appearance of the product more ornamental. At the same time a layer of light blue zinc powder is plated on the outside of the soundproof plate so that the overall landscape effect of it will be improved, and this makes the product look not so stiff.

\subsubsection{Pricing strategy}

According to different consumption subject different product pricing strategy is chosen. The method of public bidding is adopted for government projects. Product price is relatively transparent. The profit of the products are kept at a stable and reasonable level, so while normal profit is maintained, it is better to offer a rational price after the production cost of the product is deducted. Under special circumstances unprofitable ways can be adopted to develop a long-term cooperation relationship with the government. For community soundproof plate construction and service sector needing soundproof measures, the product can be sold at a higher premium to improve the level of corporate profits.

\subsubsection{Channel strategy}

Soundproof products are different from other products or services, and it belongs to the special construction materials. Consumers involved are relatively fixed, and they are primarily the government, the residential property management and service sector needing soundproof effect. So way of marketing is single. The method of direct selling is suitable for the characteristics of the product itself.

\subsubsection{Promotion strategy}

The price of soundproof product is determined by comprehensive factors such as cost of the product, equipment losses and labor. Generally speaking the price is relatively fixed. Only large-scale construction orders are possible to have the corresponding discount.

\section{Conclusion}

\subsection{The market prospect of noise barrier is vast}

On the one hand, with the rapid and stable development of economy, Chinese Road, rail and air transport industry will usher in the golden period of road construction, which means the road that need to install the insulation section increase, and this phenomenon objectively promotes the development of sound insulation screen industry. On the other hand, with the increasingly high demands on the life quality, noise pollution has become an important issue. Many NPC representatives proposed a bill aimed at noise pollution at the annual meeting of the Chinese People's Political Consultative Conference from 2012 to 2014, and the demand of one community near the road on installing sound insulation screen increases too.

\subsection{The independent development can be established based on the existing resource}

In the early stage, the company can smoothly get through challenges through imitating product characteristic of Beijing Senseshixing. However, the company need to rely on its ability of independent development of production to keep 
growing. Therefore, they need to establish their own image in the industry, continue to strengthen the innovation ability on the basis of reduced cost and exploit their own business and customer.

\subsection{Perfecting marketing system and maximizing marketing resource}

A problem of maximizing corporate profits the sound insulation screen obstacle is the product sales, the company's ability to solve this problem determine whether this company can develop rapidly or not. Therefore, the company should actively develop new customers and new resources based the advanced information network, such as register their own website on the Internet and put related information products on the Internet, only do this can make customers intuitively understand products and contact us.

\section{References}

1. Siyu Lin, Ma Zhong. "Restless City: Noise Pollution Issue”, Ecological Economic, June 2014.

2. Weiwei Liu. "Current Situation of Noise Pollution and Controlling Research in Dalian”, Green Technology, April 2014.

3. Wei Meng, Fuchen He. "Current Situation of Ambient Noise in Fushun City and Its Control Countermeasure", Liaoning's Urban Environmental Science, April 2006.

4. Lirong Zhang, Zhijun Wen, Dongchuan Wang. " Measure Research of

5. Jun Xiao, "Low Carbon Energy Saving and Decreasing Bibration Insulation of New Material Makes the Care More Quiet”, Bird's Eye View of World Environments, July 2012.

6. Li Ma, "High Performance Highway Acoustic Barriers", Building Materials Information, July 2013.

7. Decai Liang, "Innovation Research of Sounds Insulation and Noise Reduction in Traffic Artery", Resource and Environmental Technology Information, June 2008.

8. Long Long, "Discuss of Upper Noise Barrier and Every Products Performance", North Traffic, 2012.

9. Expert group of Noise Barriers Information Portal, "Noise Barriers Technology and Material Selection Manual" Beijing: China Machine Press Files, August 2011.

10. Yunfen Wang. "Road Traffic Environmental Engineering”. Beijing: People’s Communications Press Files, 2001.

11. Fuqing Dan. "Highway Construction and Environmental Protection Research", Harbin:University of The Northeast Forestry Press Files, 2010.

12. Wentang Ren, “Traffic Noise and Control”, Beijing: People's Communications Press Files, 1984.

13. Fvkuda T, Ozawa S. "Propagation of Compression Ware in a Long Tunnel With Slab Tracks", Quarterly Report of RTRI, 2005, 46(3): pp.188-193.

14. Howe Ms, Iida T. "Rapid Calculation of the Compression Wave Generated by a Train Entering a Tunnel With a Vented Hood", Journal of Sound and Vi-bration, 2006, 297(1): pp. 267-292. 